Journal Port Science Research vol:2, No:1, 2019

$\overline{\text { PAPER } ・ \text { Full original article online Free }}$

\title{
The performance of HTML5 in e-learning
}

\author{
Raed Sami Sarhan
}

Directorate of Baghdad Education Karkh III, Ministry of Education, Baghdad, Iraq Raidsami28@gmail.com

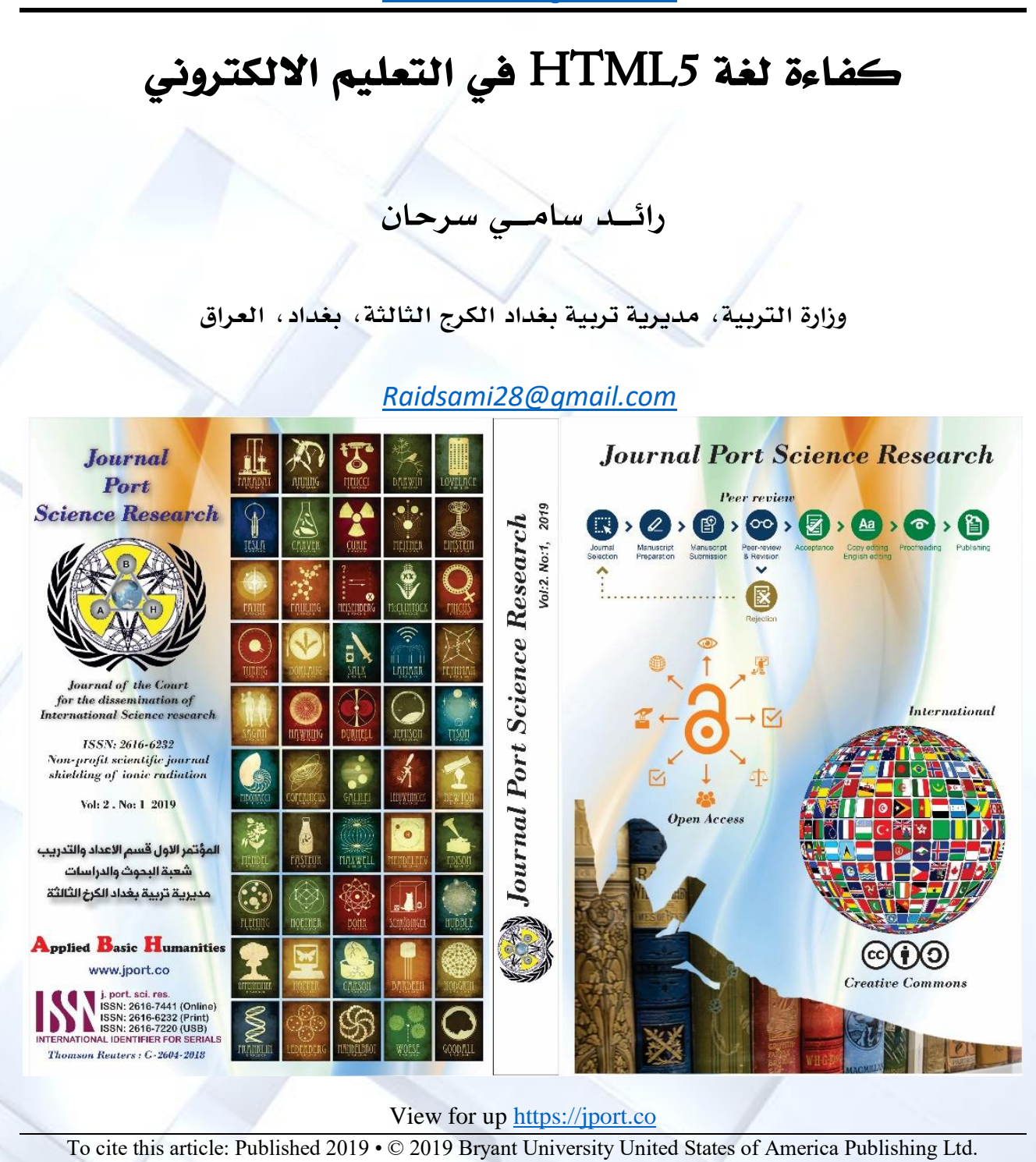


Ministry of Education Iraqi Directorate of Education Baghdad Karkh III

First Conference Department of Preparation and Training Division of Research and Studies

وزارة التريية العراقية مديرية تريية بغداد الكرخ الثالثة المؤتمر الاول قسم الاعداد والتلدريب شعبة البحوث واللدراسات

\title{
The performance of HTML5 in e-learning
}

\author{
Raed Sami Sarhan \\ Directorate of Baghdad Education Karkh III, Ministry of Education, Baghdad, Iraq \\ Raidsami28@gmail.com
}

\begin{abstract}
After Adobe announced that in 2020 it will stop supporting Flash for mobile devices, the need for a second language is becoming necessary. HTML5 is one of the hot web technologies and is widely accepted across mobile devices and the web. It is designed to deliver everything you want to do around the Internet without the need for additional software such as components Browser. It used to create incredibly complex applications, supports multimedia on mobile devices and works on all portable operating systems and responds to all screen sizes. It is advantageous to cache offline, and the important thing is that most of the major e-learning tools available on the market are almost compatible with it.
\end{abstract}

Keywords: Adobe, HTML5, Portable devices.

\section{كفاءة لغة HTML5 في التعليم الالكتروثي}

\author{
رائــلد سامــي سرحان \\ وزارة التربية، مديرية تربية بغداد الكرج الثالثة، بغداد، العراق \\ Raidsami28@gmail.com
}

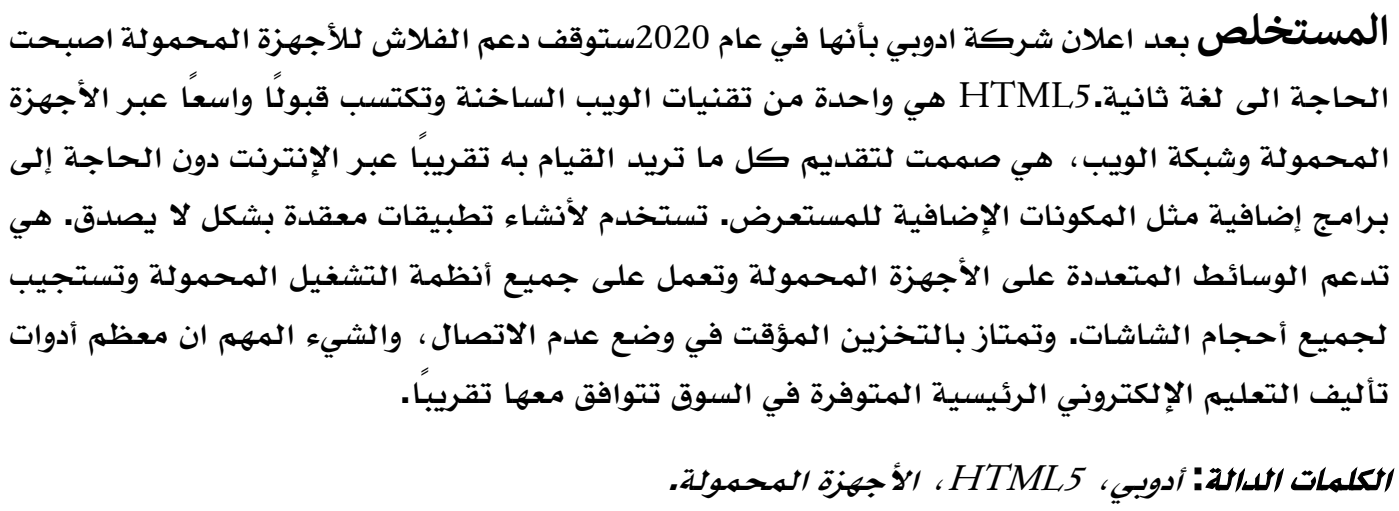




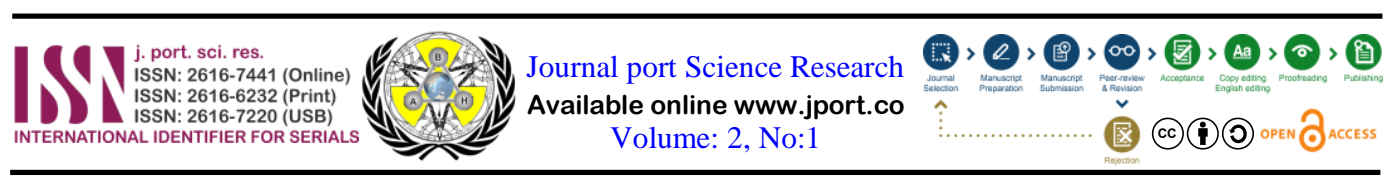

\section{Introduction}

"the latest version of Hypertext Markup Language is html5"[1]. It is considered one of the hot web technologies that gained a wide acceptance across mobile and web. In fact, HTML5 is three kinds of codes: html which is a code that create the basic structure, cascading style sheets which deals with presentation and JavaScript which makes things happen. The purpose behind the design of HTML5 is to provide almost everything the user wants to get through the network without having to add additional software. It can be used to build amazing applications applicable to your browser. In fact, the act of animation, applications, and movies can be done by HTML5. Moreover, HTML5 is not related to an owner. so, using it cost very little. It is also cross- platform, which means it can work by using any available means of communication such as a smart phone or tablet, a netbook, notebook or ultra-book or a Smart TV. Other uses of HTML5 are writing web applications that still works when users not connected to the web; telling websites where your location is; handling high definition video and delivering extraordinary graphics. The various functionalities give HTML5 a distinct edge over flash in developing online learning content [2]. Almost all the well-known names give support to HTML5, to name a little Chrome, Safari, Opera and Internet Explorer but they do not all support the same things. The widest selection of html5 features is generally supported by Firefox, later; chrome and Safari gave the same support, which has to say HTML5 is the most recent adaption of each browser. Flash player, which made the uniformity of content possible, is computer software for using content created on the Adobe flash platform, its responsibility comprises all website intros with full blast volume that may scare to death visitors. Although flash player had a good run, its eventual end is around the corner and this due to html5 that gives mobile its compatibility and provides cool features that give developers the ability to set videos and strengthen interactivity [3].

\section{What is E-Learning}

It is hard to give an accurate definition to E-learning, as it is so board and encompassing. Most definitions have a slight difference, but we can define it as " the use of any electronic technology to aid in the acquisition and development of knowledge and understanding in order to positively influence behaviors". [4] In brief, it is a learning system based on formalized educational programs using communications devices. Internet and computers are the major devices used for achieving this vital task and that means there is no need for classroom as the case with educational institutions. Elearning can also be described as the transfer of skills and knowledge which can be delivered at different times to all those who make use of E-learning. Earlier it was not widely accepted because of the lack of human element required in learning.

Because of the progress in technology and in learning system, E-learning is now accepted by the masses. Computers, smartphones, tablets were the main reason behind this revolution. These devices now have an important place in classrooms, as a result, electronic materials like pen drivers and discs are gradually taking the place of books. As the interact is accessible anywhere and anytime, knowledge can be shared and conducted via it. No doubt, E-learning has proved to be a vital means in the field of corporation's sector. Across the globe, professionals and employees can get training programs to gain necessary skills while being in a boardroom or while having seminars. Using Elearning devices in school is a step ahead for those who still use the traditional means in learning process.

Traditional ways of teaching with books and lectures should be given an equal importance, but we should not ignore the increasing importance of E-learning. Completely as it is believed that human brain can easily relate to what is seen or heard via moving pictures and videos. In addition to the fact that visuals attract that attention of student, they are also instilled in their minds for longer time. Finally, E-learning helps in the progress of nations, that is why most governments and nongovernmental sectors related to most social activities are taking into consideration the concept of Elearning [5].

سرحان، رائسد سامسي. (2019). كفاءة لغة HTML5 في التعليم الاكتروني. Journal Port Science Research، 2(1) ، 
Versions of HTML

The first version of HTML had no number; it was just called "HTML". Its purpose was to create simple web page, and this began in 1989 and achieved its goal in the year 1995 when the Internet Engineering Task Force (IETF) standardized HTML. The same year witnessed the birth of HTML 2.0. The next version of HTML was presented in 1997 the World Wide Web Consortium (W3C), it was HTML 3.2 which was followed by HTML 4.0 in 1998 and 4.01 in 1999. After that the W3C declared that it would stop creating new version of HTML and would begin to focus on extensible HTML instead; XHTML. Their recommendation was that web designers should use HTML 4.01 for HTML documents. Development split off around this point. In and after year 2000, the (W3C) concentrated on XHTML1.0 and recommended XHTML basic, but designers found a difficulty in dealing with invariable structure of XHTML and this led the "Web Hypertext Application Technology Working Group" (WHATWG) to start working on a flexible version of html and thus HTML5 was initiated [6].

\section{Effect of HTML5 in e learning}

HTML5 was developed to solve the problems of harmony and compatibility, which has a notable influence on the current standard, HTML4. In fact, HTML5 can be considered as a revision of (HTML), a Hypertext Markup language that describes the appearance and contents of web pages. The biggest difference, one of many, between HTML5 and old forms of the standard is that the old ones require proprietary plugins and APIs, that is why when building and testing a web page in a certain browser, we find a difficulty in loading it in another browser. HTML5 make loading elements easier by providing one common interface. This means the element will run by itself and there is no need to install a flash plugin in (HTML5).

Support for multimedia is one of the design goals of HTML5. New syntactic features were initiated to support this goal on mobile devices i.e. HTML5 introduces new tags to accommodate the interactive nature of the web. Moreover, and to change the way users can really interact with documents, HTML5 introduce new features including: [7].

- New set of instructions used to tell algorithm what kind of data as were wanting to extract out of his documents.

- New characteristics

- Removing redundant characteristics

- Drag and drop images and texts from one HTML5 file to another

- Enabling enhanced messaging

- Analyzing texts into logical syntactic components

- Registering protocol handler for web application and MIME

- Data storage standard in SQL databases

- Modifying while offline

Because HTML5 a new standard and because of all the above-mentioned features introduced by it, HTML5 in E-learning is the future stream in E-learning world, but we still wonder will it be capable to stand up to the ever-well-known flash? The fact that HTML5 is the new standard might answer this question because it is essential for professionals in E-learning to get on boat and start using it in order to combine and associate with E-learning developed characteristics. Online training output will also be in hands of businesses via HTML5 courses instead of flash, this means that they will certainly be seeking E-learning professionals familiar with HTML5 tools [8].

131 It is worth noting that there will be 4.68 billion mobile users by the end of 2019. Due to the fact, that Flash does not work in mobile at all, more than $50 \%$ of web content is viewing via mobile phones and this leads us to conclude that more users will be prepared to view E-learning courses on mobile phones. HTML5 has the ability to interact with all screen sizes and to work on all mobile operating systems, which means that when a professional has courses in HTML5, users can start it at work

Sarhan, R. (2019). The performance of HTML5 in e-learning. Journal Port Science Research, 2(1), 129-139. 


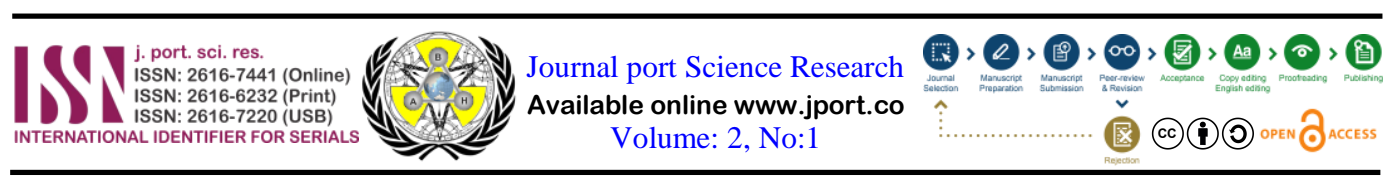

using a desktop and finish it on a mobile phone or a tablet with almost a smooth transition. One another important advantage is offline caching; it is a completely new feature of HTML5 that gives web masters the ability to define the files that a visitor can save for offline reading, so they can review the content at any time. Another characteristic of HTML5 is that it is multilingual. Each year, our world is getting smaller and smaller and with the help of technology, we can limit language problems and reach more people. When developing an E-learning course it is very important to take into consideration the localization, but Flash might cause the localization process to be very challenging when translating the strings, it can often be a confusing process and importing back these translated strings into the course might cause even more problem, such problems can be very apparent and recognizable if the language is a right-to-left one or it has a non-Latin letters as in Chinese and Arabic.

In contrast, HTML5 took into consideration the importance of localization, because HTML5 enables users to communicate effectively with multi languages, courses became much easier and quicker in HTML5, TAT and level of frustration can be reduced for everyone involved. Moreover, HTML5 gives users the chance to create more apparent code by supporting geolocation and improving semantic tags. This code in return makes the interpretation of the content easier. Flashbased courses will be useless sooner or later with the millennial generation having a complete perception and experiences on mobiles. That is why existing legacy flash content should be migrated to HTML5 that supported on all devices. Moreover, courses in HTML5 can be presented on desktops and laptops. With the help of this blog, you will have aboard overview how articulate storyline helps in creating online E-learning courses quickly that convert Flash-based courses. It will also go deep into the benefits of using your future eLearning projects when you are in need to convert E-learning courses and production to HTML5. Providing the HTML5 outputs is best done by Articulate. It makes online courses as effective as possible for those who use mobile devices. Existing features have been increased and new features have been added by Articulate 3 and storyline 360. These additional features offered greater HTML5 have been done amazingly by Articulate Storyline. Simplicity and ease of operation must be taken into consideration while choosing an authoring tool. In addition to its pleasing outlook, Articulate Storyline is also intuitive and not difficult to use. Anyone familiar with ppts can work on storyline as it virtually carves has no learning. Moreover, storyline has a power point- like interface i.e. it is standalone-authoring tool. Users must get some training on a few aspects of the tool before working on it such as inserting quizzes and interactivities and working with triggers and variables. [9]

The tool has several operative responsive templates, which can be considered one of the main advantages of storyline. Learning sources are made easy to use and modified by such templates. For each course, you are free to add custom-made templates individually. Also, interactivities are accompanied with a set of inbuilt templates. Precious cost, time, and effort can be saved with these templates while flash-based legacy is converted.

The major benefit of all main authoring tools found in markets is they are compatible with HTML5. Furthermore, they don't need plugins to access videos, audio, interactivities, and they are able to present multi-device courses. Several integrating features are also introduced by HTML5 like video and audio tags as well as canvas elements and scalable vector graphics (SVQ). When flash course is converted to HTML5, all the learns needs can be met. The publishing of courses to HTML5 is made possible by Articulate- a storyline with an assurance that cross-device compatibility is taken care of in the background automatically.

Storyline can create course with HTML5 as well as converting legacy course. It is a vital authoring tool when considering the conversion of legacy flash-based course, so for all future learning projects articulate storyline should be attempted [10]. The preferred tool for creating HTML friendly online learning is storyline and this is due to options such as HTML only output. Suck options increase browser support and improves gesture support within HTML5 tablets. There is no doubt that Elearning courses that use articulate storyline work well on all devices and that HTML5 output is as good as if not better than Flash output. A ready- to-use and very helpful responsive template usually

سرحان، رائسد سامسي. (2019). كفاءة لغة HTML5 في التعليم الاكتروني. Journal Port Science Research، 2(1) ، 
comes with articulate storyline. What is needed to be done is to import these templates and to place your content on the slides, by using such templates a lot of time can be saved, efforts and cost when converting your flash-based legacy courses [11]. The fully functional interactivities of such imported templates is the reason that makes this advantage obtained, to name a little of these interactivities, click-on-tabs, click-on-numbers.

\section{HTML5 Tools for eLearning}

After the announcement of Adobe, that it will no longer develop Flash player for mobile devices. Developers of E-learning are left astounded how to port their audio-visual content to HTML to support mobile devices and tablets and because this area rapidly and constantly the following technology when they perform their own researches and testing [12].

1) Articulate storyline: convert power point-to-HTML instead of flash.

2) Adobe Wallaby: an application responsible for turning FLA files into HTML5.

3) PopcornJS.org: an open source for HTML5 media developers or it can be described as a tool for creating HTML5 audio/visual.

4) Adobe Rome: a tool for content creation and publishing, the same as Popcorn, but it different in that it is from Adobe instead of Mozilla.

5) Dreamweaver Timeline: responsible for creating animation in a web page, it has a tool for HTML Timeline.

6) jQuery and CSS: responsible for creating custom content for the client.

7) Demo: shows text and audio by using HTML5

Flash is on the way out, although it has historically been a popular publishing standard for E-learning courses. In 2020, support for flash will be phased out as it was announced by adobe, and it has already posed some serious issues for content developers. In previous versions of storyline, some of the interactive elements in a course might not work when published to HTML5, but they would work in flash, but in recent versions of HTML5, nearly all features are supported courses published to HTML5 deliver smooth animations and transitions, complex interactivity and high-performance media play back.

With much practice, learners will gain a coherent knowledge, no matter the kind of device they are using. For active learners, HTML5 makes use of the latest technologies that support mobile gestures such as swipe, pinch-to-zoom and more. Furthermore, the rebuilding of HTML5 rendering engine has made major improvements to accessibility features. All of these features used to be available only in flash output, but now they are also supported in HTML5 [13].

Now a days, HTML5 E-learning authoring tools have becomes an industry standard. That having been said. It is very vital for all E-learning clients to have knowledge and experience of the accessible options in the E-learning authoring tool market. For the above-mentioned reason, I would like, in this research to provide you with ultimate list of HTML5 E-learning authoring tools the Elearning has to offer [14].

\section{1) Adobe Captivate}

Among the most popular HTML5 E-learning authoring tools comes Adobe Captivate which is used for creating E-learning content such as software demonstration, software simulations, branched scenarios and randomized quizzes in small web formats (SWF) and HTML5 formats, (Release 2019)

2) Elucidate

Another popular HTML5 E-learning authoring tool is Elucidate. It is designed to help institutions and freelancer deliver responsive E-learning courses; another important use of Elucidate is designing E-learning courses for various industries such as selling, customer's needs, and services, soft skills, leadership, and training.

Sarhan, R. (2019). The performance of HTML5 in e-learning. Journal Port Science Research, 2(1), 129-139. 


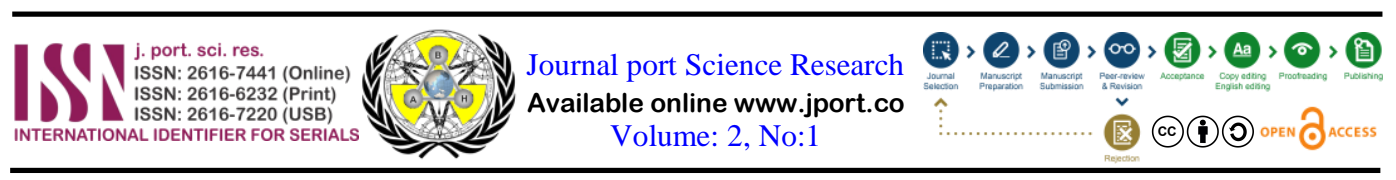

3) Articulate Storyline 360

The numerous advanced features of articulate storyline 360 are the reason that makes it one of the most vital and reliable HTML5 E-learning authoring tools. These advanced features make optimization and mobile responsiveness for playback possible on all devices. It can be used for easy collaboration and fast simulation .

\section{4) Goma Learning}

A responsive HTML5 learning authoring tool that allows learning teams around the world to make the E-learning production process faster and more collaborative. it makes the creating, delivering and updating e-learning content easier. it submits a learning suite that involves indispensable features users need to create and organize on E-learning courses .

\section{5) ITy Studio}

ITy Studio can be seen as the first authoring tool for simulations as well as for serious games, it is quite impressive as it can create games with accurate simulation and interactive maps. It also applicable to various audiences, that who are concerned with instructional designers and content development or multimedia editing .

6) Easy generator

Easy generator is an all-in-one, cloud-based HTML5 E-learning authoring software. It doesn't merely create E-learning courses, it allows users to apply their designs in the course.

\section{7) Adapt Authoring Tool}

The Adapt authoring tool is a server-based application used to allow users to quickly built responsive E-learning content. It has a great playback features across all devices, and has an intuitive interface, Sharable Content Object Reference Model (SCORM) compatibility also using it with a well-known learning management system is not that complicated. An important feature of adapt HTML5 tool is that it is fit to be used by both people who have little programming experience and developers.

8) Adobe Animate CC

The best HTML5 tool is Adobe Animate CC. The creation of interactive animated content can be easily obtained with the help of this tool. It is the best authoring tool for this purpose as it characterized by excessive self-satisfaction in the market.

\section{9) Agyria eLearning Authoring Module}

Nowadays in the market of an E-learning authoring tool, HTML5 e-learning authoring tools are a standard. Realizing this truth very well, Agyria has come up with Agyria E-learning authoring Module which can create high-quality HTML5 based E-learning content. Microsoft and Deloitte as company clients can approve it success.

10) Area9 Learning Platform

As well as it is a reporting system, it is an end-to-end E-learning, design and reporting system that integrates with learning management systems.

11) Brainshark

Brainshark is an influential HTML5 authoring tool, creating mobile responsive courses is one of its characteristics. Brainshark offers a sales enablement platform and product suite 


\section{Recommendations}

Establishing e-learning platforms for curriculum that taught in schools and it should be available to all student in the Internet or educational television Providing elearning, tools such as equipment, halls and experts according to a plan of action and benefiting from The knowledge and skills of the countries that came before us in this field, Spreading the concept and utility of E-learning in society through the educational system and the media because it will change a lot in society.

\section{References}

[1] Marshall, C. (2017). Full lowdown on HTML5 and why it's important for the web. Retrieved Date 2019 from https://www.techradar.com/news/internet/web/html5-what-is-it-1047393

[2] HTML5 Introduction, (What is New in HTML5?). (2019). Retrieved from https://www.w3schools.com/html/html5 intro.asp

[3] HTML5 is the Future of E-Learning. (2019). Retrieved from https://www.transperfect.com/blog/learning/html5-the-future-of-elearning

[4] What is eLearning? | eLearningNC.gov. (2019). Retrieved from http://www.elearningnc.gov/about elearning/what_is_elearning/

[5] Definition of E-learning | What is E-learning? E-learning Meaning - The Economic Times. (2019). Retrieved from https://economictimes.indiatimes.com/definition/e-learning

[6] Kyrnin, J. (2019). Why There Are Different Versions of HTML, (HTML 5 has become the accepted standard for web pages). Retrieved from https://www.lifewire.com/why-different-htmlversions-3471349

[7] Rouse, M. (2014). Enterprise architects' guide to success with mobile apps for business "Enterprise architects' guide to success with mobile apps for business". Retrieved Date 2019 from https://searchmicroservices.techtarget.com/definition/HTML5

[8] Enterprise architects' guide to success with mobile apps for business "ELEARNING AUTHORING TOOLS / 6 Benefits Of Using HTML5 In eLearning". (2014). Retrieved Date 2019 from https://searchmicroservices.techtarget.com/essentialguide/Enterprise-architects-guide-tosuccess-with-mobile-apps-for-business

[9] HTML5 is the Future of E-Learning "The TransPerfect E-Learning \& Development Group". (2019). Retrieved from https://www.transperfect.com/blog/learning/html5-the-future-of-elearning

[10] Samuel, J. (2018). Flash to HTML5: Articulate Storyline to the Rescue. Retrieved from Date 2019 http://www.elearninglearning.com/articulate/flash-to-html5-conversion/?open-article-

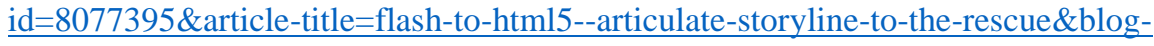
domain=commlabindia.com $\&$ blog-title $=$ commlab-india

[11] Kumar, A. (2018). Why Use Articulate Storyline to Convert Flash-based Courses to HTML5 eLearning. Retrieved Date 2019 from https://blog.commlabindia.com/elearningdevelopment/articulate-storyline-to-convert-flash-to-html5-elearning 
[12] Johnson, S. (2013). HTML5 Tools for eLearning - eLearning Network. Retrieved Date 2019 from https://elearning.net/html5-tools-for-elearning-2/

[13] Community Team. (2019). Why We're Excited About the New HTML5 Output in Storyline and What It Means for You - E-Learning Heroes. Retrieved from https://community.articulate.com/articles/why-we-re-excited-about-the-new-html5-output-instoryline-and-what-it-means-for-you

[14] Pappas, C. (2017). The Ultimate List of HTML5 eLearning Authoring Tools (2017 Update) eLearning Industry. Retrieved Date 2019 from https://elearningindustry.com/the-ultimate-list-ofhtml5-elearning-authoring-tools

سرحان، رائسد سامسي. (2019). كفاءة لغة HTML5 في التعليم الاكتروني. Journal Port Science Research، (1)، ، 